\title{
Endoloop Versus Endostapler Techniques in Appendicular Stump Closure during Laparoscopic Appendectomy: A Prospective Randomized Trial

\author{
Hamada Rashad Mohamed Abdelkader*
}

Department of General Surgery, Faculty of Medicine, Al-Azhar University, Egypt.

Consultant General Surgery, General Surgery Department, King Khaled Hospital, Hail, KSA.

*Corresponding author: Hamada Rashad Mohamed Abdelkader, Mobile: (+20)01003902869, E-Mail: dr_7mada79@yahoo.com

\begin{abstract}
Background: There has been an ongoing debate regarding the ideal method of appendicular stump closure during laparoscopic appendectomy. Objective: We conducted this study to compare endoloops and endostaplers as stump closure methods regarding postoperative infectious complications. Patients and methods: This prospective study included 110 patients diagnosed with appendicitis and scheduled for laparoscopic appendectomy. According to the stump closure method, they were divided into Group A or the endoloops group and Group B or the endostapler group. All cases received the same standard perioperative care. Preoperative, intraoperative, and postoperative data were collected, and the incidence of postoperative intraabdominal abscess was our primary outcome.

Results: Both groups showed statistically comparable findings regarding most of the demographic, clinical, and laboratory variables. Complicated appendicitis was detected in $29.09 \%$ and $36.36 \%$ of patients in groups A and B, respectively. Operative time was also comparable between the two groups (50 and 55 minutes, respectively). An intraabdominal abscess was detected in only one patient in group A (1.82\%). Wound infection was encountered in two patients in each group (3.64\%). The incidence of infectious postoperative complications was statistically comparable between the two groups. No need for reoperations and no port-site hernias were detected in our study.

Conclusion: Both endoloops and endostaplers have comparable intraoperative and postoperative outcomes. The surgeon should use the method he is more experienced with and according to the available facilities.

Keywords: Endoloops, Endostaplers, Intraabdominal abscess, Laparoscopic appendectomy.
\end{abstract}

\section{INTRODUCTION}

Acute appendicitis is the commonest intraabdominal surgical emergency, and appendectomy is one of the most performed procedures in the field of general surgery $(\mathbf{1}, \mathbf{2})$. Currently, laparoscopic appendectomy is considered the gold standard management option for the management of this disease. This is due to the known advantages of laparoscopy over laparotomy, including faster recovery, less postoperative pain, better cosmoses, shorter hospitalization period, earlier return to work ${ }^{(3,4)}$. Furthermore, laparoscopy allows better exploration of the whole abdomen and pelvis, making it easier to detect and manage any associated disease ${ }^{(4,5)}$. There is an ongoing debate about the ideal method used for appendicular stump closure, especially some surgeons believe that the method of closure is strongly related to postoperative infectious complications ${ }^{(\boldsymbol{6})}$. Nevertheless, this topic lacks substantial evidence, and the existing researches handling this topic yielded conflicting results ${ }^{(7,8)}$.

Both endoloops and endostaplers are frequently used for appendicular stump closure during the laparoscopic procedure ${ }^{(9,10)}$. Some surgeons prefer to use endostaplers to ensure proper and safe sealing of the stump. However, others prefer the endoloops because of their safety, feasibility, and low economic cost ${ }^{\text {(11-13). }}$

Despite the previous advantages, both of these two closure techniques have their drawbacks. The endostaplers have a high cost, and it requires the insertion of a 12-mm trocar for its entry. In addition, leaving metallic clips on the stump could be a risk for adhesive bowel obstruction ${ }^{(1,14)}$. On the other hand, endoloops require more manipulation of the appendicular stump and carry a slippage risk, especially in patients with complicated appendicitis, when the appendicular base is inflamed and friable ${ }^{(\mathbf{1 1}, \mathbf{1 5})}$.

As there was no consensus about the ideal method for stump closure, we conducted the current study to compare endoloops and endostaplers as stump closure methods regarding postoperative infectious complications.

\section{PATIENTS AND METHODS}

The current prospective study was conducted at King Khaled Hospital in Hail, KSA, during the period between January 2019 and December 2020.

Power Analysis and Sample Size software program (PASS) version 15.0.5 for Windows was used to calculate the sample size. We used the data published by van Rossem $\boldsymbol{e t}$ al. ${ }^{(6)}$ with the incidence of the postoperative intraabdominal abscess following laparoscopic appendectomy for acute uncomplicated and complicated appendicitis as the primary outcome. The null hypothesis was considered the presence of statically significant superiority of the endostapler group compared to the endoloop group. According to van Rossem et al. (6), the incidence of postoperative intraabdominal abscess in complicated cases was $11.7 \%$ in the endoloop group and $9.6 \%$ in the endostapler group. A non-inferiority margin of $25 \%$ was set as the target difference between both study groups. A sample size of 50 patients in each group was needed to achieve $80 \%$ power in the proposed study using a one-sided $\mathrm{Z}$ test, with a significance of 5\%. Five percent drop-out patients 
were expected. Therefore, a total of 55 patients were included in each group.

We included a total of 110 patients aged between 10 and 60 years, diagnosed with acute appendicitis, either complicated or non-complicated, and scheduled for laparoscopic appendectomy during the study period. Complicated cases were defined by the presence of perforation or necrosis of the appendix. Conversely, we excluded patients beyond the previous age range, who had previous lower abdominal surgery, having other causes of abdominal pain rather than appendicitis, or having a contraindication for laparoscopic surgery. Additionally, patients diagnosed with appendicular phlegmon, mass, or abscess were also excluded. The included patients were randomly allocated into two equal groups (55 patients in each) according to the method of stump closure; Group A included endoloops patients, and Group B included the endostapler patients. The closed envelope method was used for randomization.

All patients were clinically assessed. Also, we ordered routine laboratory investigations (including complete blood count, urinalysis to exclude urinary tract infection, and urine pregnancy test for women in the child-bearing period). Radiological investigations included pelviabdominal ultrasonography, whereas pelviabdominal computed tomography was ordered in some doubtful cases. After confirming the diagnosis, the rest of the routine preoperative laboratory parameters were ordered, including liver and kidney functions, random blood sugar, and bleeding profile.

All operations were performed by the same surgical team under general anesthesia after keeping NPO for 6 hours. After abdominal insufflation, a 10-mm supraumbilical port was used for telescope insertion in both groups. In the endoloops group, two working 5-mm ports were inserted, one at the lower left abdomen and the other at the upper right abdomen. Division of the mesoappendix and the appendicular artery was done using either ligasure or harmonic scalpel. After completely freeing the appendix down to its base, one or two loops were placed at the appendicular base, and a clip was placed distal to the loop. The appendix was divided between the loop and the clip either with scissors or using the same hemostatic device used for mesoappendix division.

In the endostaplers group, the same steps were done but with some differences. A 12-mm port was used as a working port in the left abdominal region, and it was used lately for endostapler introduction. The other two ports were the same regarding site and size. After dissecting the mesoappendix, the endostapler was fired at the appendicular base. Blue cartridges of 35- or 45$\mathrm{mm}$ length blades were used. In both groups, any detected abscess or collection was drained. Good wash and hemostasis were performed at the end of the operation, and the appendix was retrieved through the 12-mm port.

After operations, the patients were transferred to the recovery room, then to the internal ward. Oral fluid intake was allowed after either 8 hours or after passing flatus if the patient assessment was remarkable. Patients were discharged when they were afebrile, maintained oral intake, and reported good pain control using oral analgesics. Antibiotic therapy was usually commenced for one week after surgery for complicated cases, while it was given only for 24 hours in uncomplicated cases.

After discharge, follow-up visits were scheduled at 1,2 , and 4 weeks after the operation, through which all patients were assessed. If any abnormality was detected or an unusual complaint was reported, the appropriate investigations were ordered. If no complications were encountered, the stitches were removed on the second follow-up visit.

The incidence of postoperative intraabdominal abscess or peritonitis was our primary outcome. The former was defined as postoperative intraabdominal fluid collection identified by ultrasound or CT imaging and requiring antibiotics, radiological, or surgical intervention. Secondary outcomes included duration of operation, intraoperative complications, duration of hospitalization, need for reoperation, and other complication rates (surgical site infection or port site hernia). Superficial surgical site infection was defined as any inflammation of the wound, even superficial erythema, requiring commencing antibiotic therapy more than the normally required period.

\section{Ethical consent:}

An approval of the study was obtained from King Khaled Hospital in Hail (Saudi Arabia) Academic and Ethical Committee. Every patient signed an informed written consent for acceptance of the operation after a complete explanation of the benefits and drawbacks of each approach. This work has been carried out in accordance with The Code of Ethics of the World Medical Association (Declaration of Helsinki) for studies involving humans.

\section{Statistical analysis}

For statistical analysis of the acquired data, IBM's SPSS Statistics (Statistical Package for the Social Sciences) for Mac OS (version 26) was used. The Shapiro-Wilk test was performed to determine whether the data distribution was normal. Quantitative variables with a regularly distributed distribution were reported as mean and SD, and those with an erratic distribution were expressed as median and interquartile range. Qualitative variables were presented as number and percentage. For normally and abnormally distributed continuous data, the Student t-test and Mann-Whitney were employed, respectively. The crosstabs function was used to perform a Chi-square test or Fisher's exact test on categorical data. All tests were carried out with a $95 \%$ confidence interval. A statistically significant $\mathrm{P}$ (probability) value was considered when it was less than 0.5 .

\section{RESULTS}

Table 1 illustrates demographic data in the two study groups. There was no significant difference between the 2 groups. 
Table (1): Demographic data of the two groups

\begin{tabular}{lccc}
\hline & $\begin{array}{c}\text { Group A - Endoloop } \\
(\mathbf{n}=\mathbf{5 5})\end{array}$ & $\begin{array}{c}\text { Group B - Endostapler } \\
(\mathbf{n}=\mathbf{5 5})\end{array}$ & P value \\
\hline Age (years) & $39.81 \pm 11.05$ & $38.54 \pm 12.3$ & 0.57 \\
\hline $\begin{array}{l}\text { Gender } \\
\text {-Male }\end{array}$ & $29(52.73 \%)$ & $30(54.55 \%)$ & \\
-Female & $26(47.27 \%)$ & $25(45.45 \%)$ & 0.848 \\
\hline BMI $\left(\mathbf{K g} / \mathbf{m}^{2}\right)$ & $28.89 \pm 2.41$ & $29.09 \pm 2.29$ & 0.656 \\
\hline Comorbidities & $4(7.27 \%)$ & $4(7.27 \%)$ & 1 \\
-Diabetes mellitus & $6(10.91 \%)$ & $4(7.27 \%)$ & 0.507 \\
-Hypertension & $10(18.18 \%)$ & $12(21.82 \%)$ & 0.346 \\
-Smoking & $2(3.64 \%)$ & $1(1.82 \%)$ & 0.558 \\
\hline $\begin{array}{l}\text { Previous upper } \\
\text { abdominal surgery }\end{array}$ & & & \\
\hline
\end{tabular}

BMI: Body mass index.

Both groups reported a similar preoperative clinical and laboratory data (Table 2).

Table (2): Preoperative clinical and laboratory data

\begin{tabular}{lccc}
\hline & $\begin{array}{c}\text { Group A - Endoloop } \\
(\mathbf{n}=\mathbf{5 5})\end{array}$ & $\begin{array}{c}\text { Group B - } \\
\text { Endostapler } \\
(\mathbf{n}=\mathbf{5 5})\end{array}$ & P value \\
\hline $\begin{array}{l}\text { Duration of symptoms } \\
(\text { day })\end{array}$ & $1(1-3)$ & $1(1-4)$ & 0.465 \\
\hline Migrating pain & $48(87.27 \%)$ & $50(90.91 \%)$ & 0.541 \\
\hline Temperature $\left({ }^{\circ} \mathbf{C}\right)$ & $37.8 \pm 1.23$ & $37.7 \pm 1.4$ & 0.691 \\
\hline WBCs $(\mathbf{1 0} / \mathbf{L})$ & $16.45 \pm 3.09$ & $17.1 \pm 3.19$ & 0.28 \\
\hline CRP $(\mathbf{m g} / \mathbf{l})$ & $39(5-97)$ & $45(6-112)$ & 0.264 \\
\hline
\end{tabular}

CRP: C reactive protein. WBCs: White blood cells.

On laparoscopic assessment, complicated appendicitis was comparable between the two groups. Operative time and intraoperative complications were also not significantly different (Table 3 ).

Table (3): Operative data in the study groups

\begin{tabular}{lccc}
\hline & $\begin{array}{c}\text { Group A - Endoloop } \\
(\mathbf{n}=\mathbf{5 5})\end{array}$ & $\begin{array}{c}\text { Group B - } \\
\text { Endostapler } \\
(\mathbf{n}=\mathbf{5 5})\end{array}$ & P-value \\
\hline $\begin{array}{l}\text { Type of appendicitis } \\
\text {-Non-complicated }\end{array}$ & $39(70.91 \%)$ & $35(63.64 \%)$ & \\
-Complicated & $16(29.09 \%)$ & $20(36.36 \%)$ & 0.416 \\
\hline Operative time & $50(45-110)$ & $55(45-120)$ & 0.162 \\
\hline $\begin{array}{l}\text { Intraoperative } \\
\text { complications }\end{array}$ & $0(0 \%)$ & $0(0 \%)$ & 1 \\
\hline
\end{tabular}

When it comes to the postoperative outcomes, all of them were statistically comparable between the two groups (Table 4).

Table (4): Postoperative outcomes

\begin{tabular}{lccc}
\hline & $\begin{array}{c}\text { Group A - Endoloop } \\
(\mathbf{n}=\mathbf{5 5})\end{array}$ & $\begin{array}{c}\text { Group B - } \\
\text { Endostapler } \\
(\mathbf{n = 5 5 )}\end{array}$ & P value \\
\hline Hospital stay & $2(2-8)$ & $2(2-3)$ & 0.252 \\
\hline Intraabdominal abscess & $1(1.82 \%)$ & $0(0 \%)$ & 1 \\
\hline Ileus & $1(1.82 \%)$ & $0(0 \%)$ & 1 \\
\hline Superficial SSI & $2(3.64 \%)$ & $2(3.64 \%)$ & 1 \\
\hline Reoperation & $0(0 \%)$ & $0(0 \%)$ & 1 \\
\hline Port-site hernia & $0(0 \%)$ & $0(0 \%)$ & \\
\hline
\end{tabular}

SSI: Surgical site infection 


\section{DISCUSSION}

Closure of the appendicular stump is a crucial step in the laparoscopic appendectomy procedure. Most serious postoperative complications result from its inadequate closure. Multiple methods were suggested for its closure during the laparoscopic procedure, including endoloops, endostaplers, intracorporeal sutures, clips, and bipolar endocoagulation (1). Of course, each method has its pros and cons.

We conducted the current study to compare endoloops and endostaplers as stump closure methods regarding postoperative infectious complications. The included patients were divided into two groups; Group A or the endoloops group and Group B or the endostapler group. As shown in the results, no significant difference was noted between our two study groups; and this ensures proper way of randomization. This should also nullify any bias that might have skewed the results in favor of one group rather than the other one.

Our findings showed a comparable operative time between the two groups. It ranged between 45 and 110 minutes in group A (median $=50$ minutes), compared to a range between 45 and 120 minutes in group $\mathrm{B}$ (median $=55$ minutes). In line with our findings, van Rossem et al.$^{(\mathbf{6})}$ negated any significant difference between the two closure techniques regarding operative time $(\mathrm{p}=0.185)$, with median values of 40 and 38 minutes in the endoloops and endostapler groups, respectively. Moreover, Miyano et al. ${ }^{(16)}$ reported that the same variable had mean values of 71 and 64 minutes in the endoloops and endostapler groups, respectively, which was statistically comparable between the two groups ( $p>0.05$ ). Escolino et al. ${ }^{(9)}$ confirmed the previous findings regarding comparable operative times (56 and 62.3 minutes in the same two groups, respectively, $\mathrm{p}=0.27$ ).

Rakić et al. ${ }^{(1)}$ reported that operative time ranged between 18 and 170 minutes in the endoloops group (mean $=48$ minutes), while it ranged between 20 and 130 minutes (mean $=55$ minutes) in the stapler group, with a significant prolongation of that parameter with endostapler use $(p=0.014)$. Contrarily, Lukish and his associates ${ }^{(17)}$ reported that stapler application led to a significant decrease in operative time in such cases. The duration of operation had mean values of 46.9 and 55.4 minutes in the endostapler and endoloops groups, respectively $(\mathrm{p}<0.05)$. The difference between these studies could be due to different patient characteristics, percent of complicated cases, and surgeon experience.

In the current study, we noted no significant difference between the two groups regarding the duration of hospitalization, which had a median value of two days in the two groups. Another study reported no significant difference between the two approaches regarding postoperative hospital stay, with mean values of 4 and 3.6 days in the endoloops and endostapler groups, respectively $(\mathrm{p}=0.06)^{(1)}$. Lukish et al. ${ }^{(16)}$ reported that the mean duration of hospitalization was 3.7 and 3.2 days in the endoloops and endostapler groups, respectively $(p>0.05)$. Additionally, other authors confirmed the previous findings. All of the previous studies confirm our findings regarding the duration of hospitalization.

When it comes to our primary outcome (intraabdominal abscess), it occurred in only one case in group A. This incidence was not enough to make a statistical difference between the two groups. In their study published in 2011 on patients with complicated appendicitis, Miyano and his colleagues ${ }^{(16)}$ detected an intraabdominal abscess only in one case in each group, with an incidence rate of $2.7 \%$ and $3.2 \%$ in the endoloop and endostapler groups, respectively $(p>0.05)$. The authors reported that all of these cases were successfully managed by IV fluids and antibiotics (conservative management). The same authors in another study reported that the same complication was encountered in $2.7 \%$ and $1.2 \%$ of patients in the same groups, respectively, with no significant difference between the two groups $(\mathrm{p}=0.47)^{(\mathbf{6})}$. Furthermore, Swank et al. ${ }^{(\mathbf{1 8})}$ confirmed the previous findings, as the same complication was detected in $4.3 \%$ and $3 \%$ of patients in the endoloops and endostapler groups, respectively $(\mathrm{p}=0.313)$.

In contrast to the previous findings, other studies reported a higher incidence of leakage and intraabdominal abscess with endoloops application, especially in complicated patients ${ }^{(9,}{ }^{19)}$. Some researchers attributed that finding to the condition of the appendicular mucosa in both approaches. It is everted with endoloops while being inverted with endostaplers (20).

In our study, superficial surgical site infection was detected in $3.64 \%$ of patients in the two study groups. In the study conducted by van Rossem and his coworkers $^{(6)}$, the same complication was encountered in $1.8 \%$ and $2.7 \%$ of patients in the endoloops and endostapler groups, respectively, with no significant difference between the two groups $(\mathrm{p}=0.378)$. Miyano et al. ${ }^{(11)}$ also reported that the same complication was detected in $2.7 \%$ and $1.2 \%$ of patients in the endoloops and endostapler groups, respectively, which was comparable between the two groups. Escolino and his associates $^{(9)}$ also confirmed these comparable findings $(\mathrm{p}=0.87)$.

We did not encounter any patients with port site hernia in our study during the scheduled follow-up period. Swank and his associates ${ }^{(18)}$ reported that the same complication was encountered in $0.9 \%$ of patients included in both groups. The difference in the followup duration between various studies could explain the differences between them.

No patients required reoperation in our study. Rakić and his colleagues ${ }^{(\mathbf{1})}$ also reported very low rates of reoperation after laparoscopic appendectomy with the same two techniques. Reoperation was needed for one case $(0.4 \%)$ and two cases $(1.9 \%)$ in the endoloops 
and endostapler groups, respectively, with no significant difference between the two groups ( $\mathrm{p}=$ 0.183). The indications were intraabdominal abscess, stump dehiscence, and ileus, respectively. However, another study reported that reoperation was performed in 14 cases $(3.7 \%)$ and two cases $(0.5 \%)$ in the endoloops and endostapler groups, respectively. The authors reported a significant elevation of reoperation rates with endoloops use $(\mathrm{p}=0.004)^{(\mathbf{9})}$. It is expected to find some differences regarding that matter, which would depend on the complication encountered.

Our study has some limitations. Initially, it was a single-center study that included a relatively small sample size. Additionally, the study lacks intermediateand long-term follow-up of the included cases. These drawbacks should be well-discussed in the upcoming studies.

\section{CONCLUSION}

According to the previous findings, both endoloops and endostaplers are safe and feasible methods for appendicular stump closure. Both techniques are associated with comparable postoperative infectious complications together with other perioperative outcomes. Therefore, the surgeon should use the method he is more experienced with and according to the available facilities.

\section{Financial support and sponsorship: Nil. \\ Conflict of interest: Nil.}

\section{REFERENCES}

1. Rakić M, Jukić M, Pogorelić Z et al. (2014): Analysis of endoloops and endostaples for closing the appendiceal stump during laparoscopic appendectomy. Surg Today, 44(9):1716-22.

2. Yaghoubian A, Kaji A, Lee S (2012): Laparoscopic versus open appendectomy: outcomes analysis. Am Surg., 78(10):1083-6.

3. Kumar S, Jalan A, Patowary B et al. (2014): Laparoscopic appendectomy versus open appendectomy for acute appendicitis: A prospective comparative study. Kathmandu Univ Med J (KUMJ), 14(55):244-8.

4. Jaschinski T, Mosch C, Eikermann M et al. (2018): Laparoscopic versus open surgery for suspected appendicitis. Cochrane Database Syst Rev., 11(11):Cd001546.

5. Jaschinski T, Mosch C, Eikermann M et al. (2015): Laparoscopic versus open appendectomy in patients with suspected appendicitis: a systematic review of metaanalyses of randomised controlled trials. BMC Gastroenterol., 15:48-53.

6. van Rossem $C$, van Geloven $A$, Schreinemacher $M$ et al. (2017): Endoloops or endostapler use in laparoscopic appendectomy for acute uncomplicated and complicated appendicitis : No difference in infectious complications. Surg Endosc., 31(1):178-84.

7. Kazemier G, in't Hof K, Saad S et al. (2006): Securing the appendiceal stump in laparoscopic appendectomy: evidence for routine stapling? Surg Endosc., 20(9):14736.

8. Sajid M, Rimple J, Cheek E et al. (2009): Use of endoGIA versus endo-loop for securing the appendicular stump in laparoscopic appendicectomy: a systematic review. Surg Laparosc Endosc Percutan Tech., 19(1):115.

9. Escolino M, Becmeur F, Saxena A et al. (2018): Endoloop versus endostapler: what is the best option for appendiceal stump closure in children with complicated appendicitis? Results of a multicentric international survey. Surg Endosc., 32(8):3570-5.

10. Ceresoli M, Tamini N, Gianotti L et al. (2019): Are endoscopic loop ties safe even in complicated acute appendicitis? A systematic review and meta-analysis. Int J Surg., 68:40-7.

11. Miyano G, Urao M, Lane G et al. (2011): A prospective analysis of endoloop $\mathrm{s}$ and endostaples for closing the stump of the appendix in children. J Laparoendosc Adv Surg Tech A., 21(2):177-9.

12. Fahrner R, Schöb O (2012): Laparoscopic appendectomy as a teaching procedure: experiences with 1,197 patients in a community hospital. Surg Today, 42(12):1165-9.

13. Safavi A, Langer M, Skarsgard E (2012): Endoloop versus endostapler closure of the appendiceal stump in pediatric laparoscopic appendectomy. Can J Surg., 55(1):37-40.

14. Nottingham J (2002): Mechanical small bowel obstruction from a loose linear cutter staple after laparoscopic appendectomy. Surg Laparosc Endosc Percutan Tech., 12(4):289-90.

15. Langer M, Safavi A, Skarsgard E (2013): Management of the base of the appendix in pediatric laparoscopic appendectomy: clip, ligate, or staple? Surg Technol Int., 23:81-3

16. Miyano G, Urao M, Lane G et al. (2011): Appendiceal stump closure in children with complicated appendicitis: a prospective analysis of endoloops versus endostaples. Asian J Endosc Surg., 4(3):116-9.

17. Lukish J, Powell D, Morrow S et al. (2007): Laparoscopic appendectomy in children: use of the endoloop vs the endostapler. Arch Surg., 142(1):58-61.

18. Swank H, van Rossem C, van Geloven A et al. (2014): Endostapler or endoloops for securing the appendiceal stump in laparoscopic appendectomy: a retrospective cohort study. Surg Endosc., 28(2):576-83.

19. Poole G (1993): Management of the difficult appendiceal stump: how I do it. Am Surg., 59(9):624-5.

20. Beldi G, Muggli K, Helbling C et al. (2004): Laparoscopic appendectomy using endoloops: a prospective, randomized clinical trial. Surg Endosc., 18(5):749-50. 